\title{
Educational Programs at DOE Research University National Laboratories
}

\author{
Xiaofei Wang ${ }^{1}$ Xiaoqi Zheng ${ }^{1}$ Weiwei Chen ${ }^{2}$ \\ ${ }^{1}$ Institute of Higher Education, School of Humanities \& Social Science, Beihang Univer- \\ sity, Beijing 100191, People's Republic of China \\ ${ }^{2}$ School of Transportation Science \& Engineering, Beihang University, Beijing 100191, \\ People's Republic of China
}

\begin{abstract}
National laboratories are important participants in providing science and technology education to both students and teachers. Several Department of Energy (DOE) national laboratories' educational programs are analyzed in this study. The mission of educational programs is to enrich science, technology, engineering and mathematics (STEM) education through programs that support the nation's scientific mission. The programs are divided into several types by audience, such as, K-12 students, high school students, teachers, undergraduate students, graduate students, and college faculty. And each type is introduced in detail. Finally, several common features of educational programs are concluded.
\end{abstract}

Keywords: Educational Program, National Laboratory, Research University

\section{The mission of educational pro- grams}

Since the 1990's, several reports have highlighted the importance of education in science, technology, engineering and mathematics (STEM) for the nation's future prosperity. In 2007, a report [1] prepared for the National Academy of Sciences stated that: "An educated, innovative, motivated workforce (human capital) is the most precious resource of any country in this new flat world."

Workforce is the most important factor for both enterprises and countries. Carrying out educational programs is a potential way for training future employees. Among the nation's most significant investments in research and development (R\&D) are some 700 laboratories funded directly by the federal government, about 100 of which are considered significant contributors to the national innovation system [2]. The largest and best known of these laboratories are run by Department of Defense (DOD) and Department of Energy (DOE). DOE manages more than 20 national laboratories \& technology centers. For the similarity, just several of DOE laboratories which are cooperated with research universities are studied.

\subsection{Missions of educational programs at different national laboratories}

The director of Los Alamos National Laboratory (LANL) Michael R. Anastasio said, "You are important to our future. It is important to us that you have a rewarding experience, and we want you to come back as either students or employees." And $25 \%$ of all LANL employees are former students or post doctors. The goal of LANL education programs is dedicated to science education in northern New Mexico and to cultivating the next generation of Laboratory employees [3]. 
Brookhaven National Laboratory (BNL) expounds the mission with more details in five aspects [4]. (1) Educate new generations of scientists, engineers, technicians, and teachers; (2) Encourage and promote science literacy; (3) Assist the scientific staff in achieving their goals; (4) Support and celebrate diversity; (5) Maintain BNL as a local, regional, national, and international educational asset.

The mission of educational programs in Argonne National Laboratory (ANL) is to enrich STEM education through programs that advance Argonne's strategic energy, environment, and security initiatives and to develop new educational programs based on transformative discovery that further Department of Energy's (DOE) workforce development and science literacy mission [5].

\subsection{Consistency with the national strategy}

As indicated in the National Academies report "Science, Technology, and the Federal Government: National Goals for a New Era", the United States needs to be among the world leaders in all fields of research so that it can:

(1) Bring the best available knowledge to bear on problems related to national objectives even if that knowledge appears unexpectedly in a field not traditionally linked to that objective.

(2) Quickly recognize, extend, and use important research results that occur elsewhere.

(3) Prepare students in American colleges and universities to become leaders who can extend the frontiers of knowledge and apply new concepts.

(4)Attract the brightest young students both domestically and internationally [6].

Educational programs at national laboratories serve for the national strategy mentioned above, educating new generation scientists, and attracting foreign researchers.

\section{Educational programs in national laboratories}

National laboratories have long been active participants in efforts to strengthen science and technology education, especially on their location places. Through their Offices of Educational Programs, the laboratories develop and offer programs for students and teachers, and connect them with the labs' varied resources. Programs range from hands-on science activities for elementary school students, to summer research workshops and internships, to professional development for teachers and college faculty.

In 2009, Brookhaven Lab educational programs served 34,781 K-12 students and 2,033 teachers from New York State. An additional 66 New York State undergraduate students participated in research internships, along with 160 others from across the country. These programs were supported by 377 researchers and staff members, who volunteer their time in addition to their work at the Lab [7].

\subsection{Types of educational programs}

The educational programs at different DOE national laboratories are similar with each other. Lawrence Berkeley $\mathrm{Na}$ tional Laboratory (LBNL) is used as an example to introduce the types of educational programs in this section. Berkeley $\mathrm{Lab}$ in the following text is another name of LBNL. LBNL divides education programs into several types by audience [8].

\subsubsection{K-12 Students \& Schools.}

LBNL provides the following programs for students in grades K-12. (1) Berkeley Lab Afterschool Science and Technology (BLAST) program is an after-school program for middle schools that aligns to the California Science Standards. (2) Berkeley Lab Adventure Zone in Elementary Science (BLAZES) program is a 3-hour workshop held on-site that provides hands-on activities, a research lab tour, 
and talks from scientist volunteers to 5 th grade classes in Bay Area. (3) Berkeley Lab Educational Visits (BLEV) usually include one- to two-hour programs aligned to the California State Science Standards, a general introduction to the Lab, an appropriate hands-on activity, and a facility tour linked to subject matter. (4) Other programs.

\subsubsection{High School Students.}

LBNL provides the following programs for high school students. (1) Nano-High program is a series of Saturday morning lectures focused on the cutting-edge scientific issues of the day, from molecular medicine to nanoscience, from climate change to astrophysics, from solar energy to the math behind Sully, Remy and Buzz Lightyear. (2) LBNL DOE Regional Science Bowl is part of the DOE's National Science Bowl. It is an academic competition of teams of high school students. (3) Berkeley Lab Educational Visits (BLEV) usually include one- to two-hour programs aligned to the California State Science Standards, a general introduction to the Lab, an appropriate hands-on activity, and a facility tour linked to subject matter. (4) Other programs.

\subsubsection{Teachers.}

LBNL provides the following programs for science teachers. (1) Industry Initiatives for Science and Mathematics Education (IISME) program provides summer science research experiences for teachers. IISME is a summer program with the possibility of a repeated appointment. (2) Global Teachers' Academy / QuarkNet. The Global Teachers' Academy improves classroom science instruction by training teachers to engage students in a technology-rich, project-based experience. QuarkNet provides professional development and on-going support for physics teachers who join the program. (3) Other programs.

\subsubsection{Undergraduate Students \& Fac- ulty.}

LBNL provides the following programs for undergraduate students and faculty. (1) Science Undergraduate Laboratory Internship (SULI) program encourages undergraduates from 2- and 4-year colleges to pursue STEM careers by providing research internships at one of 17 DOE National Laboratories. (2) Science Teacher And Researcher (STAR) program places undergraduates interested in becoming science and mathematics teachers in paid internships in Science and Engineering. Participants work with scientists or engineers on projects related to the Lab's research programs. (3) Visiting Faculty Program (VFP), formerly called Faculty and Student Teams (FaST), is intended to support the professional development of current faculty members who have the desire to increase the competitiveness of their own independent research at their home institution through scientific research collaborations with DOE laboratory scientists. (4) Community College Internship (CCI) program seeks to encourage community college students to enter technical careers relevant to the DOE mission by providing 10 -week internships at one of 13 DOE Laboratories. (5) Berkeley Lab Undergraduate Research (BLUR) program places students from 4 year institutions in paid internships in science and engineering. Participants work with scientists and engineers on projects related to the Lab's research program. (6) Berkeley Lab Undergraduate Faculty Fellowship (BLUFF) program brings faculty to LBNL for an extended period to work with Lab investigators as a continuation of a collaboration established while previously participating in the Visiting Faculty Program (VFP). (7) DOE Office of Science Graduate Fellowship (DOE SCGF) program supports outstanding students to pursue graduate training in fundamental research in areas 
of physics, biology, chemistry, mathematics, engineering, computer and computational sciences, and environmental sciences relevant to the Office of Science and to encourage the development of the next generation scientific and technical talent in the U.S. who will pursue careers in research critical to the Office of Science mission at DOE laboratories and in academia. (8) Other programs.

\subsubsection{Berkeley Lab Employees.}

LBNL provides the following programs for Berkeley Lab employees and their families. (1) Daughters and Sons to Work Day (DSTW) program hosts children of employees for a day of science and fun. (2) Berkley Lab In School Settings (BLISS) Resource Center provides workshops, activities, literature and other resources available to Berkeley Lab employees to enable them to be ambassadors for science education in their community.

(3) Other programs.

LBNL provides abundant programs for different types of audience. Students, teachers, college faculty, and Lab employees all can participate in these programs.

\subsection{Organization}

An agency such as Office of Educational Programs manages educational programs in each DOE national laboratory. The Educational Programs Organization Chart in ANL is shown in Fig. 1 [9]. There are a manager and an administrative secretary who manage several divisions, and these divisions also have a head and several members who manage specific programs.

The organization charts in different Labs have different forms, but the main structures are similar.

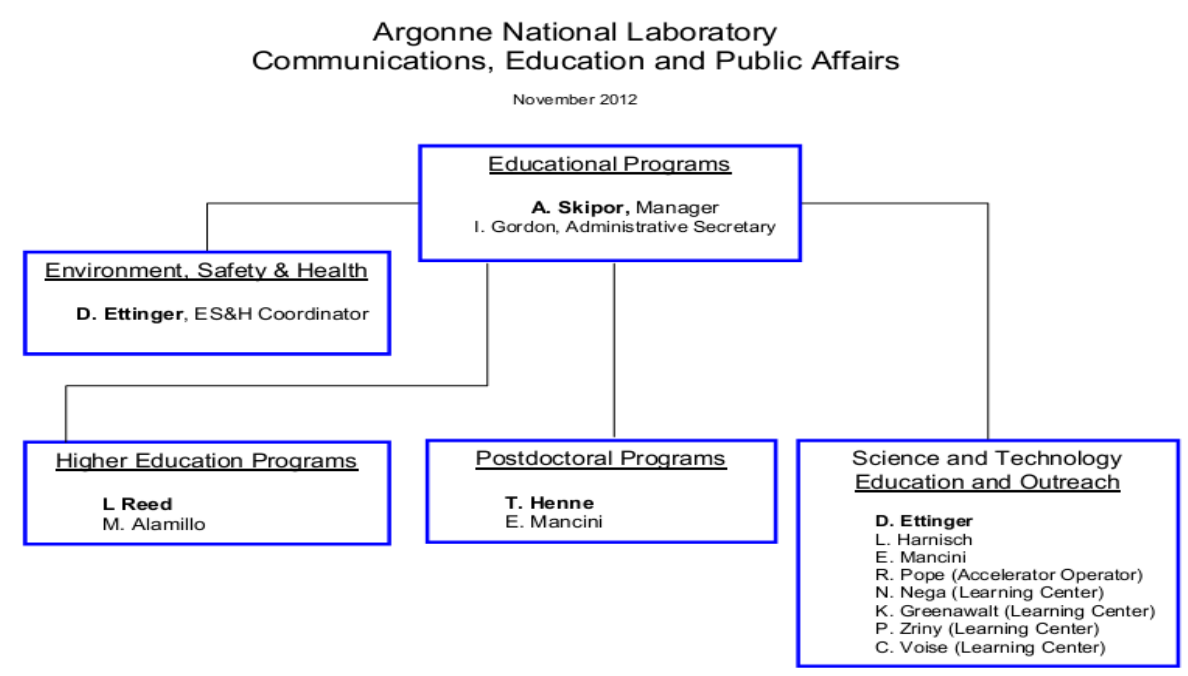

Fig. 1: ANL Educational Programs Organization Chart [9].

\subsection{Application}

Office of Educational Programs develops and offers programs to students and teachers. The calendar of educational programs is posted on the national laboratories' official website. Applicants can select suitable programs and deliver their application forms online.

ANL Educational Programs Calendar of 2012 is shown in Tab. 1 [10]. There are abundant programs for different audiences throughout the year. 
Tab. 1: ANL Educational Programs Calendar of 2012 [10].

\begin{tabular}{|c|c|}
\hline Schedule & Program \\
\hline January 16 - April 27 & Spring Undergraduate Internships \\
\hline February 17 & Rube Goldberg Competition \\
\hline February 18 & Science Bowl Academic Competition \\
\hline February 23 & Introduce a Girl to Engineering Day \\
\hline April 14 & Science Bowl Car Competition \\
\hline April 19 & Science Careers in Search of Women Conference \\
\hline May 29 - August 3 & Summer Undergraduate Internships \\
\hline June 11 - August 3 & Pre-College Research Participation Program \\
\hline July 23 - 27 August 6 - 10 & Sustainability Workshop for Middle School Teachers \\
\hline August $4-11$ & Exotic Beam Summer School \\
\hline August $12-25$ & National School on Neutron and X-ray Scattering \\
\hline September 4 - December 14 & Fall Undergraduate Internships \\
\hline September 20 & Postdoctoral Research Symposium \\
\hline September 21 & Postdoctoral Career Fair \\
\hline October 26 & Undergraduate Research Symposium \\
\hline
\end{tabular}

\section{Conclusions}

National laboratories' goals are not only to satisfy the national strategic target requirements, carry out frontier basic researches, and promote technology transfer, but also to educate new generations of scientists \& engineers, build scientific literacy of citizens, and use the resources of these Labs effectively.

Through investigating the educational programs at DOE national laboratories, several common features are concluded.

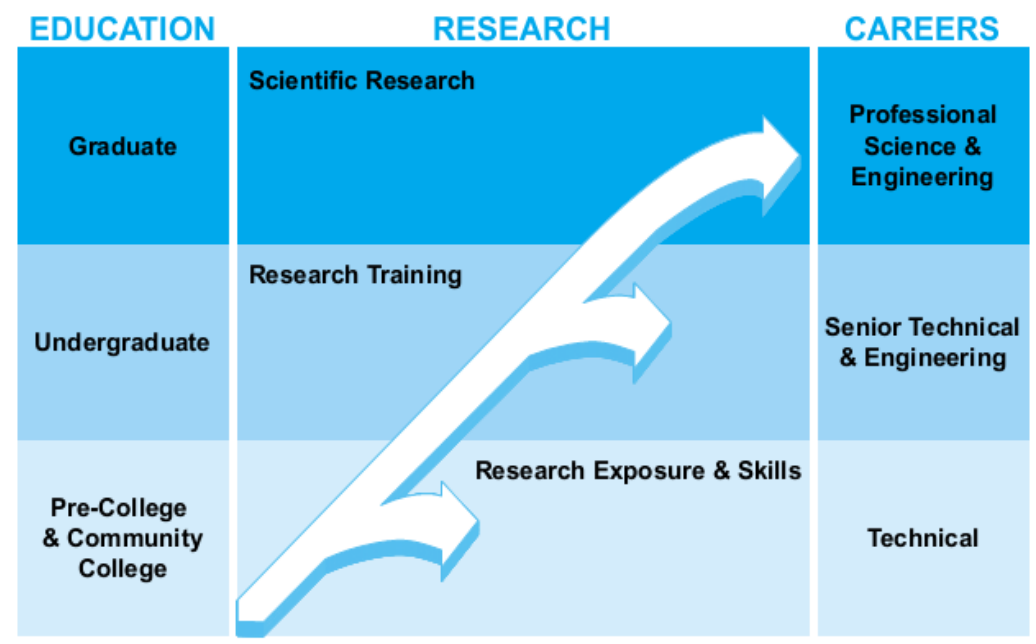

Fig. 2: LLNL integration of education, research, and career options [11]. 


\subsection{Meeting the nation's needs.}

Education in STEM has become a focus of intense concern within the business and academic communities. Educational programs at national laboratories meet the nation's needs.

\subsection{Educating future outstanding sci- entists \& engineers}

National laboratories have excellent scientists, advantaged facilities, international leading research results, and superior research environment. Students who participate in the programs can take part in real science research projects and obtain guidance from mentors.

\subsection{School-to-career guidance.}

For different types of students, Lawrence Livermore National Laboratory (LLNL) Science \& Technology Education Program (STEP) provides different research training and careers guidance as shown in Fig. 2 [11].

\subsection{Using the resources of these Labs effectively.}

Students with scientific aptitude should have opportunities at the national laboratories and facilities where they can obtain the specialized research skills and handson experience working on projects that are unique to government research and development. It is also in the nation's best interest for the Labs to use their resources to enhance public understanding of science.

\subsection{Scholarship \& funds.}

DOE and its national laboratories provide scholarship \& funds for outstanding graduate and undergraduate students to pursue training in fundamental research. The goal is to encourage more distinguish students to pursue careers in research critical to the DOE mission and in academia.

\section{Acknowledgements}

This work is financially supported by the Beijing Municipal Commission of Education Project (0107001). The authors also wish to thank Professor Hua Tian for helpful discussion.

\section{References}

[1] National Academy of Science, "Rising Above the Gathering Storm, Energizing and Employing America for a Brighter Economic Future," Report, 2007.

[2] M. Crow and B. Bozeman, "Limited by Design: R\&D Laboratories in the U.S. National Innovation System," New York: Columbia University Press, 1998.

[3] Los Alamos National Laboratory, "Los Alamos National Laboratory Education Programs," Report, 2008.

[4] http://www.bnl.gov/education/mission .asp

[5] http://www.dep.anl.gov/

[6] NAS/NAE/IOM, "Science, Technology, and the Federal Government: National Goals for a New Era," Washington, DC: National Academy Press, 1993.

[7] Brookhaven National Laboratory, "Brookhaven National Laboratory Economic Impact Report," Report, 2010.

[8] http://csee.lbl.gov/Programs/

[9] http://www.dep.anl.gov/about/educati on-orgchart.pdf

[10] http://www.dep.anl.gov/calendar.ht $\mathrm{m}$

[11] http://education.llnl.gov/files/reports /STEP_Annual_Rpt_FY00.pdf 